\title{
Research of Double Closed Loop PID Control Strategy of Road Feeling Motor
}

\author{
Jing Zhou ${ }^{1, a}$, Zhixiong $\mathrm{Lu}^{1, \mathrm{~b}^{*}}$ \\ ${ }^{1}$ College of Engineering, Nanjing Agricultural University, China \\ azhoujing306@163.com, 'rluzx@njau.edu.cn
}

Keywords: Steer-By-Wire; road feeling motor; double closed loop; platform test

\begin{abstract}
One apparent advantage of Steer-By-Wire (SBW) system is that its road feeling characteristic can be designed freely. Whether the road feeling characteristic is able to be formed effectively depends on the control effect of road feeling motor (RFM). When a RFM is working under the condition of plugging around or reversing around, the back electromotive force (BEMF) will occur in the circuit which will interrupt the RFM's control ability. Thus in this paper, a double closed loop (DCL) PID control strategy based on torque and current was designed in order to improve the RFM's control ability. Then, transfer functions of the RFM and the steering wheel system (SWS) were obtained, a simulation model was established via Simulink ${ }^{\mathrm{TM}}$, and a road feeling simulation system test platform was built so as to verify the effectiveness of the control strategy. The results of step response tests and sine followed tests show that: the DCL PID control strategy can effectively eliminate the control negative effects caused by BEMF of the RFM, which make the output torque error be in the range of $\pm 0.5 \mathrm{~N} \cdot \mathrm{m}$, which can meet the control requirement of RFM.
\end{abstract}

\section{Introduction}

Steer-By-Wire (SBW) system replaces mechanical connections between SWS and road wheel by signal wire [1], which helps to enlarge legroom in driver's cab in order to improve driving comfort [2] and avoid that the impact caused by road roughness will transfer to driver directly in order to reduce the energy consumed by driver [3], and provides variable angle ratio which can change the road feeling characteristic freely according to driver's preference and driving safety requirements [4].

The "road feeling" provided to driver has to be generated by a particular device, since there are no mechanical connections between SWS and road wheel by signal wire. Thus, in a SBW system, how to react the motion and force both of tire and the whole vehicle is the most important issue for road feeling design [5]. The most common way is to generate the road feeling by a RFM whose value is controlled by a controller to match the force on steering wheel [3].

Currently, there are many researches about RFM control method. Wu Jungan et al. [6] designed a DCL series control strategy based on torque and currency, in which conventional PID is used as control algorithm. This control system had certain responsiveness and following performance, which was verified by stimulation tests, but bench tests did not be completed.

Luo Shijun et al. [7] used BP neural network to find an optimal combination of PID parameters, due to its arbitrary nonlinear expression ability, adaptive learning ability, parallel distributed processing and high robustness and fault tolerance. The test results showed that the controller has good tracking performance.

Qiu Xuyun et al. [8]designed a road feeling controller based on linear active disturbance rejection control, in order to reduce the disturbance in system and simplify the mathematic 
modeling. The results showed that, the controller has a high robustness and accuracy, but the structure of the controller is so complicated that it hasn't been proved to be effective by platform tests.

Based on the analysis of the characteristics of road feeling of SWS system, a feasible control strategy is designed to obtain ideal road feeling, which has been verified by stimulation and platform test.

\section{Mathematical model of the SWS}

In this section, a mathematical model of the system was obtained according to its structure and the type of the RFM.

2.1 Mathematical model of steering structure. Figure 1 displays the SWS which consists of steering wheel, RFM, torque sensor, and reducer, et al.

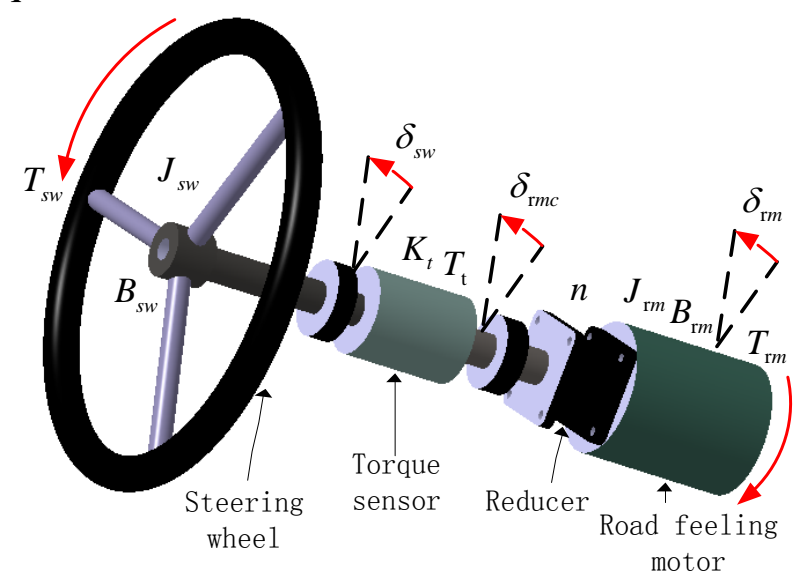

Figure 1. The structure of SWS

By Newton's mechanics law, the following relations were obtained:

$$
\begin{aligned}
& T_{s w}-K_{t}\left(\delta_{s w}-\delta_{r m a}\right)=J_{s w} \ddot{\delta}_{s w}+B_{s w} \dot{\delta}_{s w} \\
& T_{t}=K_{t}\left(\delta_{r m a}-\delta_{s w}\right)
\end{aligned}
$$

which were applied to the Lagrange equation:

$$
T_{s w}(s)+T_{t}(s)=J_{s w} \delta_{s w}(s) s^{2}+B_{s w} \delta_{s w}(s) s
$$

$T_{s w} \quad$ Torque applied by driver $(\mathrm{Nm})$

$B_{s w} \quad$ Damping coefficient of the steering column $(\mathrm{Nm} /(\mathrm{rad} / \mathrm{s}))$

$J_{s w} \quad$ Moment of inertia of the SWS $(\mathrm{kg} \cdot \mathrm{m} 2)$

$\delta_{s w} \quad$ Angle of the steering wheel (rad)

$K_{t} \quad$ Stiffness coefficient of the torque sensor (Nm/rad)

$T_{t} \quad$ Torque obtained by torque sensor (Nm)

Rewriting Eq. (3):

$$
G_{0}(s)=\frac{\delta_{s w}(s)}{T_{s w}(s)+T_{t}(s)}=\frac{1}{J_{s w} s^{2}+B_{s w} s}
$$

According to the reduction ratio of reducer, Eq. (5) and (6) were obtained: 


$$
\begin{aligned}
& \delta_{r m}=n \delta_{r m a} \\
& T_{r m}-J_{r m} \ddot{\delta}_{r m}-B_{r m} \dot{\delta}_{r m}=K_{t}\left(\delta_{r m c}-\delta_{s w}\right) / n
\end{aligned}
$$

which were applied to the Lagrange equation:

$$
n^{2} T_{r m}(s)-K_{t}\left(\delta_{r m}(s)-n \delta_{s w}(s)\right)=n^{2}\left(J_{r m} s^{2}+B_{r m} s\right) \delta_{r m}(s)
$$

$\delta_{r m c} \quad$ Angle of the torsion bar applied by the RFM (rad)

$n \quad$ Reduction ratio of reducer

$J_{r m} \quad$ Equivalent moment of inertia of the RFM $(\mathrm{kg} \cdot \mathrm{m} 2)$

$B_{r m} \quad$ Damping coefficient of the RFM $(\mathrm{Nm} /(\mathrm{rad} / \mathrm{s}))$

$T_{r m} \quad$ Electromagnetic torque of the RFM (Nm)

$\delta_{m c} \quad$ Angle of the RFM (rad)

The transfer function of the steering structure was obtained:

$$
G_{1}(s)=\frac{\delta_{r m}(s)}{n^{2} T_{r m}(s)+n K_{t} \delta_{s w}(s)}=\frac{1}{n^{2} J_{r m} s^{2}+n^{2} B_{r m} s+K_{t}}
$$

2.2 Mathematical model of the RFM. The RFM in this system is brushless DC torque motor (90LWX03) which is a two-phase conductive and star-connected motor with a three-phase six-state.

In order to facilitate the modeling and simulation analysis, it was assumed that the stator current, the three-phase winding, and the rotor magnetic field of this motor were exactly symmetrical, and its air gap magnetic field was square wave, and at the meanwhile its eddy current and hysteresis loss were ignored [9]. Thus, the voltage balance equation of stator armature winding and the electromagnetic torque balance equation were obtained:

$$
\begin{aligned}
& U_{r m}-K_{r m e} \dot{\delta}_{r m}=(L-m) \dot{I}_{r m}+R I_{r m} \\
& T_{r m}=K_{r m t} I_{r m}
\end{aligned}
$$

which were applied to the Lagrange equation:

$$
U_{r m}(s)-K_{r m e} \delta_{r m}(s) s=(L-m) \dot{I}_{r m}(s) s+R I_{r m}(s)
$$

$U_{r m} \quad$ Voltage of the stator armature winding of the RFM (V)

$K_{r m e} \quad$ BEMF coefficient of the RFM (V/ $\left.(\mathrm{rad} / \mathrm{s})\right)$

$L \quad$ Inductance of the winding of the RFM $(\mathrm{H})$

$m \quad$ Mutual inductance of each two windings of the RFM $(\mathrm{H})$

$R \quad$ Resistance of the winding of the RFM $(\Omega)$

$I_{r m} \quad$ Current of the stator winding of the RFM (A)

$K_{r m t} \quad$ Electromagnetic torque coefficient of the RFM (Nm/A)

The transfer function of the RFM was obtained:

$$
G_{2}(s)=\frac{I_{r m}(s)}{U_{r m}(s)-K_{r m e} \delta_{r m}(s) s}=\frac{1}{(L-m) s+R}
$$




\section{Control strategy design}

In this section, a control strategy of the SWS was designed. Also the method of parameter tuning was given.

3.1 Structure of control strategy. The RFM is working under the condition of plugging around or reversing around, which means the actual rotational direction operated by driver is opposite to the motor's theoretical rotational direction. In this case, the BEMF occurring in circuit will interrupt the control ability of the RFM.

Fig. 2 shows the structure of a DCL PID control strategy based on torque and current, so as to improve this control ability.

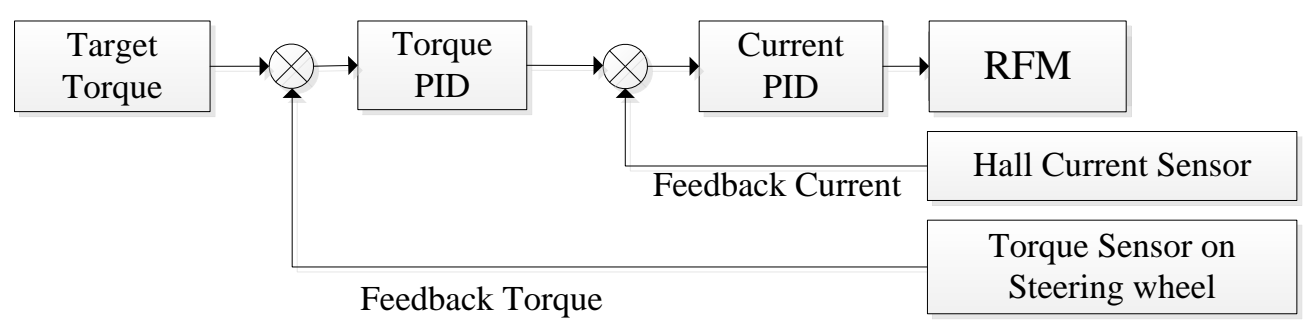

Figure 2. Control strategy diagram of RFM

Fig. 3 shows the PID closed loop control principle of the RFM's current.

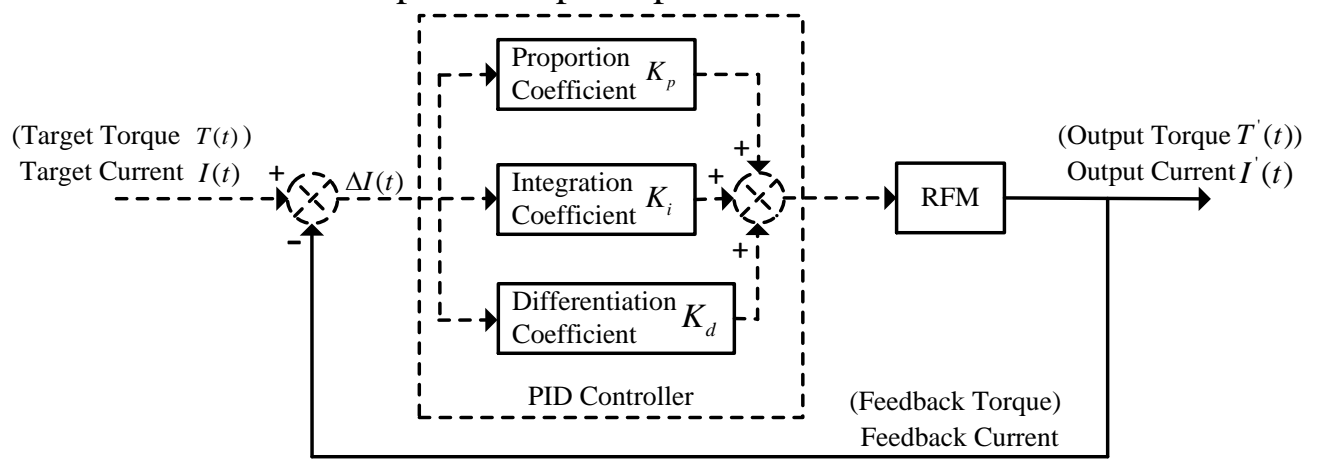

Figure 3. Control principle diagram of RFM

3.2 Parameter tuning. In this paper, the PID parameters were tuned by the combination of simulation and experiment of following research. The steps were, the PID parameters of current layer were set to $\mathrm{P}=1, \mathrm{I}=0$, and $\mathrm{D}=0$ firstly, after the PID parameters of current layer being tuned, then the PID parameters of current layer would be tuned again. The final tuned PID parameters are shown in Table I.

Table I The DCL PID control parameters

\begin{tabular}{lllllll}
\hline Closed loop layer & \multicolumn{3}{l}{$\begin{array}{l}\text { the PID parameters of torque } \\
\text { layer }\end{array}$} & $\begin{array}{l}\text { the PID parameters of current } \\
\text { layer }\end{array}$ \\
\hline parameter & $\mathrm{P}$ & $\mathrm{I}$ & $\mathrm{D}$ & $\mathrm{P}$ & $\mathrm{I}$ & $\mathrm{D}$ \\
value & 3.2 & 0.04 & 0.005 & 1.8 & 0.02 & 0.001 \\
\hline
\end{tabular}

\section{Establishment of stimulation model and test platform}

4.1 List of main components. All main components working in the road feeling stimulation model and their parameters are shown in Table II. 
Table II Main components and their parameters

\begin{tabular}{lllll}
\hline Components & Type & Symbol & Value & Unit \\
\hline $\begin{array}{llll}\text { Steering } \\
\text { wheel }\end{array}$ & non & $J_{s w}$ & 0.045 & $\mathrm{Kg} \cdot \mathrm{m}^{2}$ \\
components & & $B_{s w}$ & 0.295 & $\mathrm{Nm}(\mathrm{rad} / \mathrm{s})$ \\
& & $J_{\mathrm{r} m}$ & 0.000235 & $\mathrm{Kg} \cdot \mathrm{m}^{2}$ \\
& & $B_{\mathrm{rm}}$ & 0.00334 & $\mathrm{Nm}(\mathrm{rad} / \mathrm{s})$ \\
& & $L$ & 0.0015 & $\mathrm{H}$ \\
RFM & $90 \mathrm{LWX}$ & $m$ & 0.0003 & $\mathrm{H}$ \\
& 03 & $R$ & 1.8 & $\Omega$ \\
& & $K_{r m t}$ & 0.15 & $\mathrm{Nm} / \mathrm{A}$ \\
& & $K_{r m e}$ & 0.15 & $\mathrm{~V} /(\mathrm{rad} / \mathrm{s})$ \\
Torque sensor & JN-DN & $K_{t}$ & 1000 & $\mathrm{Nm} / \mathrm{rad}$ \\
Reducer & PL60 & $n$ & 5 & $\mathrm{Non}$ \\
\hline
\end{tabular}

4.2 Establishment of stimulation model. Fig. 4 shows a stimulation model of the SWS which was established based on Simulink ${ }^{\mathrm{TM}}$ according to the related transfer function and all component parameters (Tab. 2).

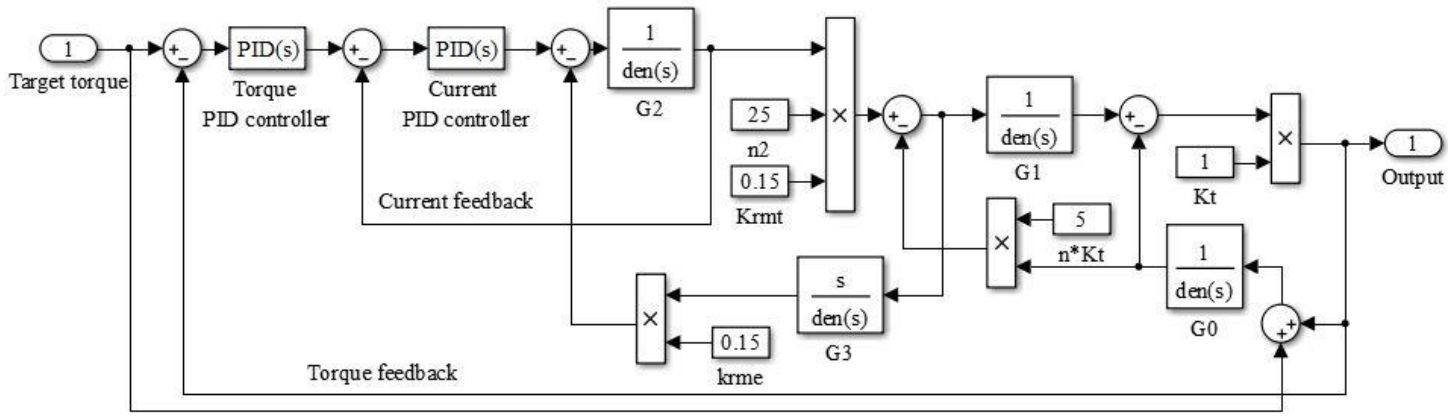

Figure 4. The stimulation model of SWS

The operating torque of driver was as the interference signal of the RFM, and it was also the target torque of the stimulation model. The torque which was obtained by a torque sensor was as the torque reference signal. The current which was obtained by the Hall current sensor of the RFM was as the current reference signal.

4.3 Establishment of test platform. Fig. 5 shows a test platform which was established according to the components listed in Table 2.

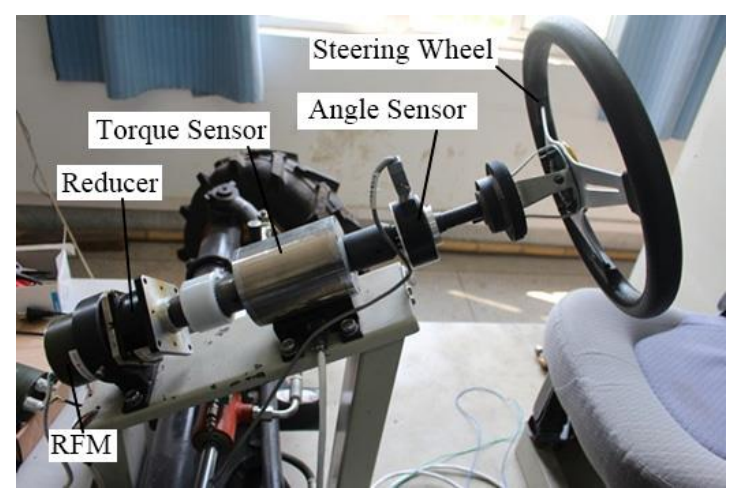

Figure 5. Test platform of SWS 
The RFM and the torque sensor were fixed in the platform. The output axis of RFM was connected with the reducer. Another axis of the reducer was connected with the rotary axis of torque sensor by a custom-designed coupling. Another axis of the torque sensor was connected with the steering wheel by a coupling. The IPA15F2K61S2 chip of STC is used as the controller of this platform. The angle sensor of steering wheel in this figure which is used in a steering-by-wire test was not be used in this research.

\section{Analysis of test results}

In this section, the simulation model tests and the platform tests were completed in order to verify the effectiveness of the DCL PID control strategy.

The target torque was produced by controller. The steering wheel was operating by driver, whose rotary direction should be ensured to opposite to the target torque all the time. When the target torque changed, a beep tone and a change of LED would prompt the driver to alter the steering wheel's rotary direction.

The results of step response test stimulating torque mutation and sine followed test stimulating torque changing continuously according to sine rule are shown in Fig. 6 and 7, respectively.

5.1 Step response test. Step response test was used to stimulate torque mutation of steering wheel. Each target torque of the stimulation test and the platform test was stepped from 0 to 5 in the 2 th seconds. After the response was stable, the target torque was stepped from 5 to 0 in the 9th seconds.

From Fig. 6, the stimulation result was relatively approximate to the target torque. The response time of both steps was $0.34 \mathrm{~s}$. There was only one overshoot and a trifling steady-state error. The platform test result was less close to the target torque, the step response time of the 2 th seconds was $0.34 \mathrm{~s}$, and the step response time of the 9 th seconds was $0.4 \mathrm{~s}$. The steady-state value during the period from 2 th seconds to 9 th seconds fluctuated intensely, and the fluctuation was basically in the range of $\pm 0.5 \mathrm{~N} \cdot \mathrm{m}$, which is because the driver cannot apparently perceive the fluctuation error while actual driving. Thus, the results proved that this strategy can meet the control requirement of step response.

5.2 Sine followed test. Sine followed test was used to stimulate the torque of steering wheel changing continuously. Both input signals of the stimulation test and the platform test were sine signal whose frequency was $12 \mathrm{~s}$, and amplitude is 8 .

From Fig. 7, both the stimulation result and the platform result were relatively ideal. The output torque of the RFM was able to accurately follow the target torque. Figure 10 shows the following error curve which is used to evaluate the following effectiveness.

From Fig. 8, the torque following error was basically in the range of $\pm 0.5 \mathrm{~N} \cdot \mathrm{m}$, which had a considerably trifling effects on the driving feeling. 950 data points were totally collected in the tests, among which 743 data points of stimulation test whose percentage is $78.2 \%$, and 710 of platform test whose percentage is $74.74 \%$ were all in the range of $\pm 0.5 \mathrm{~N} \cdot \mathrm{m}$. Thus, the results proved that this strategy can meet the control requirement of sine following. 


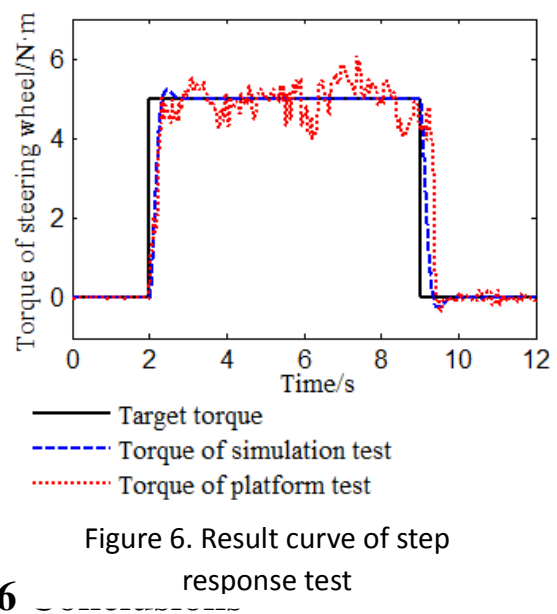

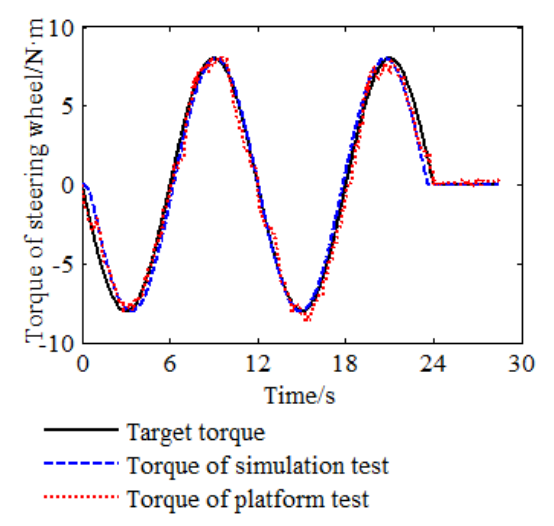

Figure 7. Result curve of sine followed test
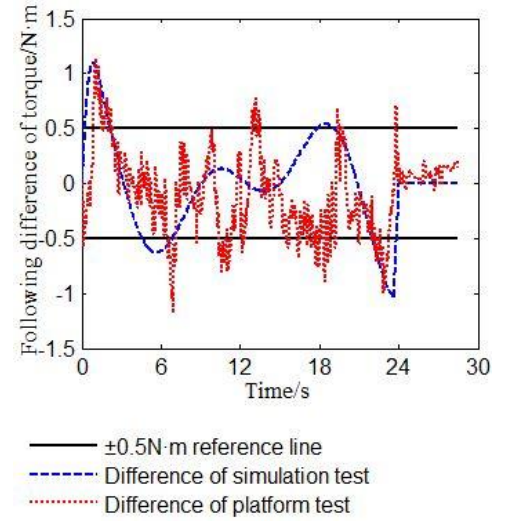

Figure 8. Following error curve of sine followed test

The control problem of RFM in SBW system was researched in this paper. Considering the condition of plugging around or reversing around when a RFM is working, which would generate the BEMF to interrupt the control ability of a RFM, a DCL PID control strategy based on torque and current was designed in this paper. A transfer function was obtained on the basis of structure of the SWS and the RFM, a simulation model was established based on Simulink ${ }^{\mathrm{TM}}$, and a test platform of road feeling simulation system was built.

The results of step response tests and sine followed tests show that: the DCL PID control strategy can effectively eliminate the control negative effects caused by BEMF of RFM. And the output torque error was in the range of $\pm 0.5 \mathrm{~N} \cdot \mathrm{m}$, which will not have an apparent influence on the driving feeling. Thus, the effectiveness of the DCL PID control strategy can be verified due to the simulations and platform tests.

\section{Acknowledgment}

This work was supported by Jiangsu province science and technology support project (No. BE2012384), all support is gratefully acknowledged.

\section{References}

[1] Zong C.F., Li G., Zheng H. Y. et al. Study Progress and Outlook of Chassis Control Technology for X-by-wire Automobile[J]. China Journal of Highway and Transport, 2013, 26(2): 160-176.

[2] Yu L.Y., Lin Y., Shi G.B. et al. Research of Angle Ratio of Steer-by-wire System. Transactions of the Chinese Society for Agricultural Machinery, 2007, 38(8): 190-192.

[3] Yang S.B. Steer-by-wire System Control Strategy Research[D]. Wuhan: Wanhan University of Technology, 2008.

[4] A. Bootz, N. Nitzsche. Vehicle Steering System of the By-wire Design Type[P]. United States Patent:0094820A1,2011-04-26.

[5] L. Peretti, M. Zigliotto. A Force Feedback System for Steer-by-Wire Applications Based on Low-Cost MR Fluids Design Hints[C]. Power Electronics, Machines and Drives. 2006, 4: 469-473.

[6] Wu J.G. Study on Road Feeling Control Strategy for Tractor Hydraulic Steer-by-wire System [D]. Nanjing: Nanjing Agricultural University, 2014.

[7] Luo S.J., Hu J. B. Study on Steering Feel of Steering-by-wire System of Wheel Loader [J]. Transactions of the Chinese Society for Agricultural Machinery, 2007, 38(7): 43-46.

[8] Qiu X. Y., Feng J. X. On Road Feel Simulation Control of Vehicle Steer-By-Wire System [J]. Control Engineering of China, 2011, 18(1): 25-28. 
[9] F.Rodriguez, E.Uy, A.Emadi. Brush-less DC Motor drive for Steer-by-wire and electric power Steering applications[J]. SAE, 2004:535-540. 